\title{
Igor Poljak
}

E-mail: ipoljak1@unizd.hr

Josip Orović

E-mail: jorovic@unizd.hr

Vlatko Knežević

E-mail: vknezevi1@unizd.hr

Maritime Department, University of Zadar, Mihovila Pavlinovića 1, 23000 Zadar, Croatia Jure Vulić

E-mail: jurevulic@gmail.com

\section{The Low Duty Centrifugal Compressor Control System and its Impact on the Surge Pressure}

\begin{abstract}
This paper presents an analysis of the low duty compressor for marine steam generators and its running conditions. The analysed low duty compressor was observed under three different running zones caused by a throttled flow towards main steam generators. All examples were explained according to real exploitation conditions. As the low duty compressor has the highest influence on the flame stability for the main steam generators while running, it is very important to observe the constant flow towards the main steam generators. Possible flow fluctuation implies instabilities which are explained in the article and the same have to be avoided in order to assure a reliable life span of the low duty compressor and smooth operation of the main steam generators. Furthermore, for preventing efficiency losses of a steam power plant, some methods for avoiding surge effects are emphasized and recommended.
\end{abstract}

Keywords: low duty compressor, operation control, surge line, running condition modes.

\section{Introduction}

A low duty compressor is used in conventional LNG steam carriers for delivery of evaporated LNG to the main steam generators, which is used for burning and steam generating for the propulsion of such plant. At the same time, the withdrawal of LNG vapour from cargo tanks maintains the pressure inside the tank at steady values where temperature is maintained constant throughout the voyage. A typical low duty compressor is an axial centrifugal compressor with one stage wheel that converts suction speed of the vapour to the delivery pressure. The flow is regulated with inlet 
guide vanes and with a frequency converter that changes the speed of electric motor. A typical LD compressor is shown in Figure 1.

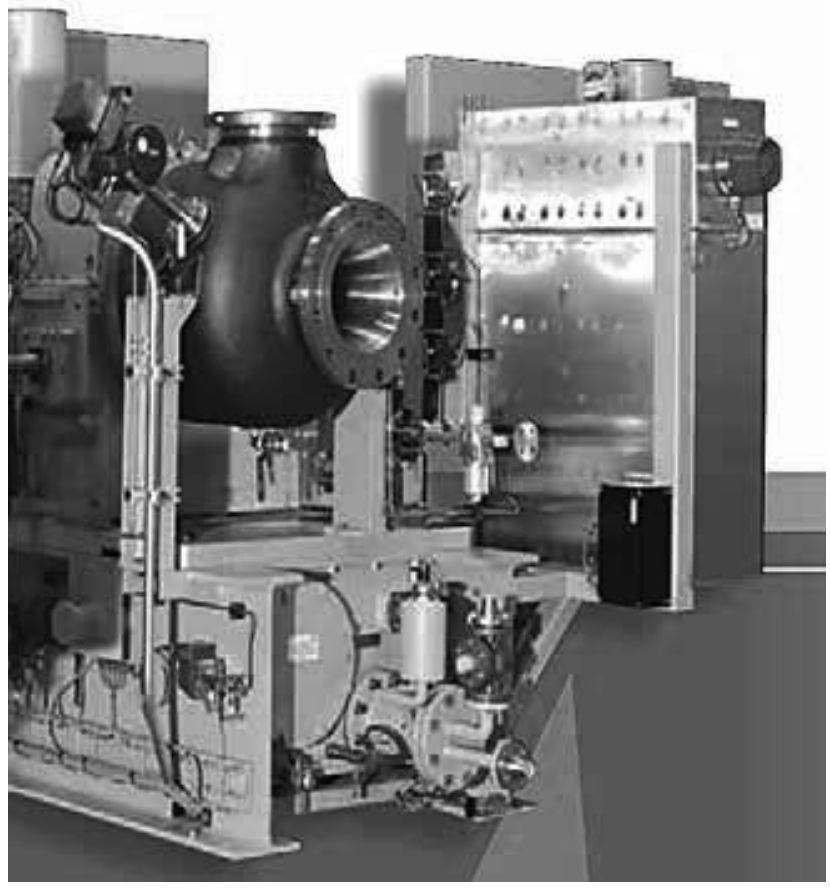

Figure 1 - Low duty compressor [1]

The efficiency and reliability of the low duty compressor have a significant role in the marine steam propulsion plant [2]. During the exploitation period some failures may occur on the centrifugal compressor with a direct impact on its working condition. The surge effect occurs at the centrifugal compressor when the delivery flow of the compressor is reduced in such a way that the pressure developed by the compressor is insufficient to continue the normal flow to the consumer, but is reversible and flows inside the compressor itself [3]. The critical point of the pressure where surge is initiated is known as the surge inception point and its location can be determined by the compressor characteristic curve near the peak of the positive flow region [4] (Figure 2). In Figure 2 point 1 represents compressor operating point with maximum flow. As the pressure increases, operating point of compressor moves from point 1 to point 2. Further pressure raises moves operating point of the compressor to the point 3. Reverse flow inside the compressor moves operating point to 4 . 


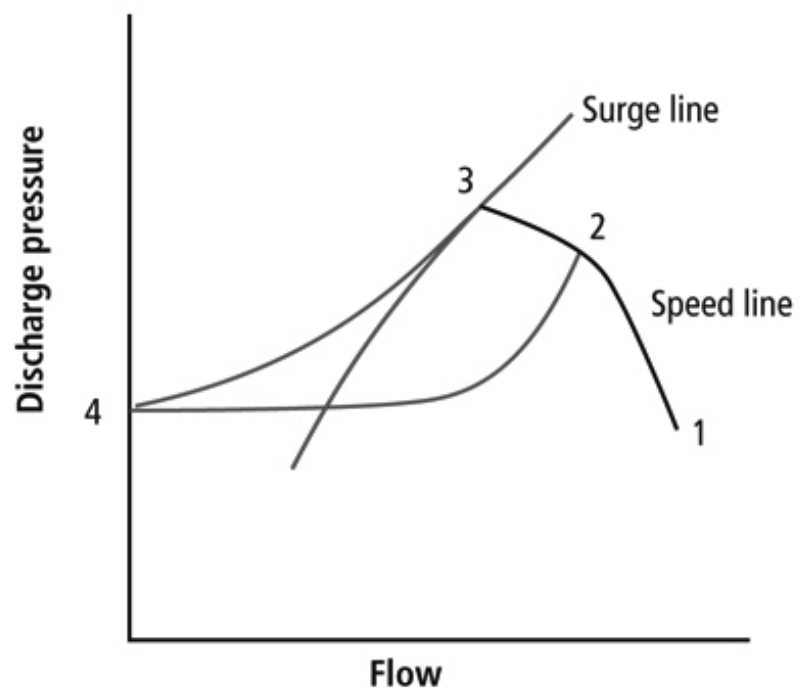

Figure 2 - Surge effect on compressor flow [5]

The repetitive nature of the surge is present all the time due to cyclic repeating of the same process under given working condition. The frequency of surging is 1-5 seconds for centrifugal compressors and 3-20 seconds for the axial compressor [6]. The negative outcome of surging is a high load on the bearings due to reversal flow, high vibration and rapid raise of the internal temperature of the gas. According to [7] it is a common industrial believe that half an hour of accumulated surge is detrimental for the compressor to be damaged beyond acceptable levels. The power range of industry compressor varies, but for the ship application the centrifugal, axial flow compressor for the steam generators fuel gas supply is in the range of about $300 \mathrm{~kW}$ [8]. For comparison purposes, industrial axial multistage compressors for the gas turbine MJ701J, which delivers $560 \mathrm{MW}$ of power [9], are of a multi stage design and consumes high power. According to [10], 55-65\% of produced power is consumed by a centrifugal axial compressor. The operation speed of the centrifugal compressor is higher if compared to other compressors, where for an aircraft operation of that range it goes from 50.000 to $100.000 \mathrm{~min}^{-1}$ [11]. For a marine application, it is below $30.000 \mathrm{~min}^{-1}$.

The produced adiabatic head for non-ideal gases is given by the following equation [11]:

$$
H_{A D}=c_{p} \cdot\left(T_{d}-T_{s}\right)
$$


Where:

$H_{\mathrm{AD}}$ - adiabatic head is in desired units, $[\mathrm{kJ} / \mathrm{kg}]$

$T_{\mathrm{d}}$ - compressor delivery temperature, $[\mathrm{K}]$

$T_{\mathrm{s}}$ - compressor suction temperature, $[\mathrm{K}]$

$c_{\mathrm{p}}-$ specific heat capacity for methane, $[\mathrm{kJ} / \mathrm{kgK}]$

The example for the calculation of adiabatic head of pure methane $\mathrm{CH}_{4}$ for the low duty compressor for pressure rise of 0,097 $\mathrm{MPa}$ in Figure 4 is given below:

$$
\begin{aligned}
& T_{\mathrm{s}}=133 \mathrm{~K} \\
& T_{\mathrm{d}}=165 \mathrm{~K} \\
& p_{\mathrm{s}}=103 \mathrm{kPa} \\
& p_{\mathrm{d}}=200 \mathrm{kPa}
\end{aligned}
$$

$$
H_{A D}=c_{p} \cdot\left(T_{2}-T_{1}\right)=2,14 \cdot(165-133)=68,48[\mathrm{~kJ}]
$$

\section{Low pressure compressor delivery and surge control}

The conventional fuel gas supply system in Figure 3 consists of a low duty compressor for compressing the boil off gas at conventional LNG carriers from cargo tanks to the main steam generators [12].

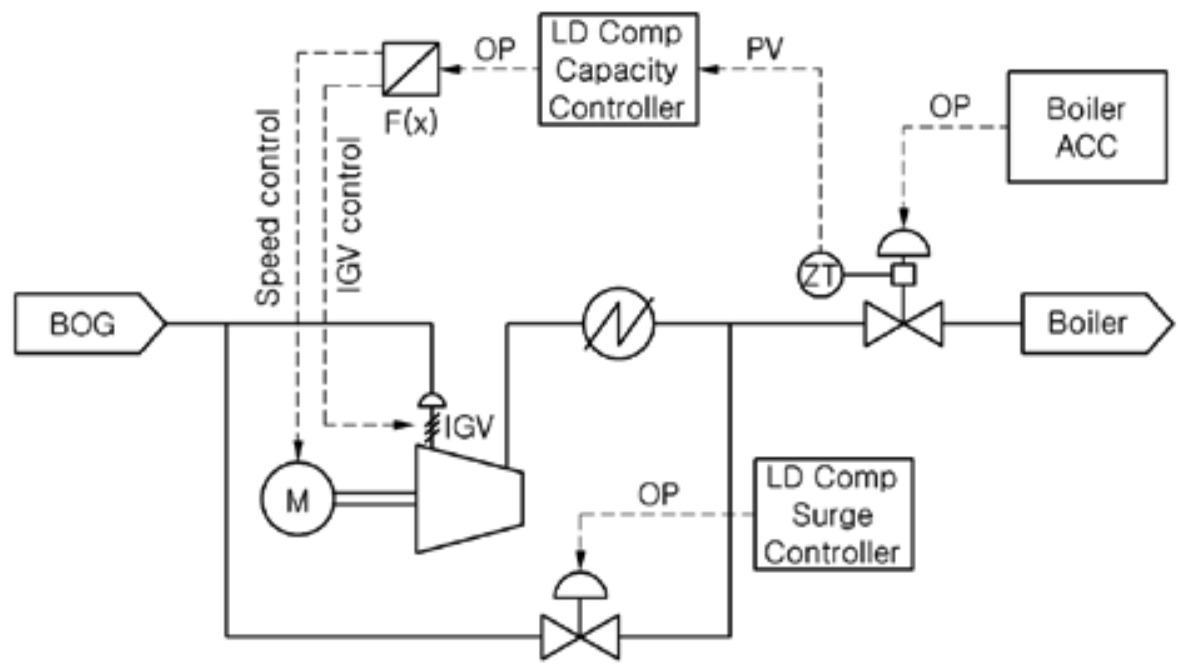

Figure 3 - Split signal control for the low duty compressor in marine application [13] 
In the same figure the following abbreviations stand for [14]:

$\mathrm{PV}$ - process value

OP - output signal

IGV - inlet guide vanes

ACC - automatic combustion control

ZT - position transmitter

BOG - boil off gas

The low duty compressor (LD compressor) delivery signal is coming from the main steam generators fuel gas demand which is controlling compressor delivery by the inlet guide vane opening position and with the compressor speed. The signal is processed according to the steam generator ACC (automatic combustion control) according to Table 1. It has to be mentioned that the manufacturer calibrates ACC valves for the normal steam generator operation in the range from 75 to $85 \%$ in open position, which assures flame stability. These steam generator gas control valves are not in a fixed position, but they are also changing position with the steam generator load change [15]. When the steam generator pressure is too high, ACC valves are closing and vice versa. Such a compressor control system is very complex due to simultaneous control of steam generators fuel gas valves, compressor rotor speed and IGV position control. When the LD compressor is stopped and fuel gas is led to steam boilers (so called free flow mode), ACC valves are controlled by the steam generators PID combustion controller. Compressor running mode is explained in Table 1.

Table 1 - Compressor delivery, in regards to running speed and IGV position [16].

\begin{tabular}{|c|c|c|c|}
\hline Compressor speed & $\begin{array}{c}\text { Main steam generator } \\
\text { fuel demand }\end{array}$ & IGV position & Volume flow \\
\hline 12.000 & $0-25 \%$ & $80-0^{\circ}$ & $1.250 \mathrm{Nm}^{3} / \mathrm{h}$ \\
\hline $12.000-24.000$ & $25-100 \%$ & $0-\left(-30^{\circ}\right)$ & $8.500 \mathrm{Nm}^{3} / \mathrm{h}$ \\
\hline
\end{tabular}

When inlet guide vanes are in fully open position $\left(-30^{\circ}\right)$, the low duty compressor guide vane position perpendicular to the gas flow stream is enhancing the gas flow to steam generators by $20 \%$ [17].

\section{Surge line for the low duty compressor at three different delivery loads}

Sudden change in the running condition of the main steam generators causes a crossing of the surge line and a backflow of the LNG through the low duty compressor as in Figure 4. 


\section{LD-ViriableSpeed Motor}

- Operating Point

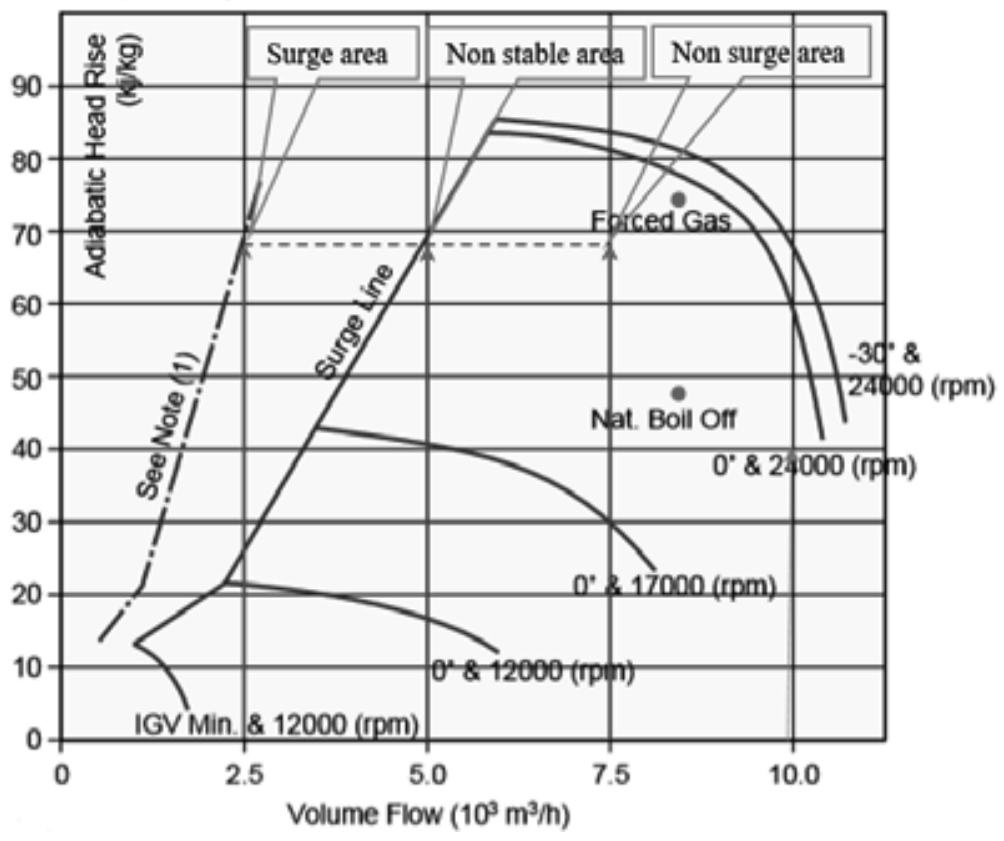

Figure 4 - Surge line and throttling of volume flow [18].

Note (1) represents the minimum flow to the steam generator when the recirculation loop is opened.

In the first case, when the compressor is running in the surge area, the gas volume flow to the main steam generators is suddenly reduced because the fuel gas demand at gas burners is decreased by closing the main steam generator ACC valves. The consequence of the reduced flow is that the compressor adiabatic head increases and passes the surge line. At this point the low duty compressor starts surging. This negative effect is prevented by opening the LD compressor surge controller, i.e. the bypass valve and the volume flow is then recirculated. Although the flow is recirculated and this condition will prevent the compressor from surging but it will not prevent the gas fuel overheating. By recirculating the gas fuel through the LD surge controller, the temperature raises due to friction and entropy generation inside the compressor. In order to limit further raise of the temperature, a safety option is provided that will trip the operation of the low duty compressor once the gas fuel temperature reaches $100^{\circ} \mathrm{C}$ by the safety control circuit [14].

In the second case, the LD compressor is running in a non-stable area that causes partial surging and partial opening of the LD compressor surge controller. In this 
running mode the compressor is protected from the negative effect of the surge, but its delivery is reduced due to the partially opened LD compressor surge valve. As the bypass valve is partially opened, the delivered volume to the main generators has lower density due to higher temperature. This results in a lower mass flow of the fuel to the main steam generators and the main generators cannot reach full load in that operation zone although the steam generator ACC valves are fully opened.

If the transition from surge to non-surge area is very fast and instant (surge valve opens and closes frequently) this will have an impact to the stability of the main steam generator steam pressure control. There will be time for a smooth changeover from the fuel gas combustion to the fuel oil combustion if required, but the surging effect will have a certain impact on the LD compressor bearings condition, rotor and other parts. On the other side, if the surge valve is not opened in such situations, the LD compressor discharge pressure will increase. This will result in a back flow of the fuel gas (surging) and not stable operation of ACC valves. In that respect it is better for the LD compressor control valve to commence opening before approaching the surge line. Opening of the surge control valve is in accordance with the differential set point (discharge pressure is compared to inlet pressure).

The third operating zone is the normal running zone and in that zone the low duty compressor delivers fuel gas to the main steam generators under normal conditions with ACC steam generator valves in the normal range from $75-85 \%$ in open position.

When the low duty compressor stops, the inlet guide vanes are at $80^{\circ}$. This means that they are fully closed but they are designed in such a way that the inlet is not fully closed. A small opening is provided which will allow the fuel gas to flow through the compressor if the inlet and outlet compressor shut off valves are in the open position, Figure 5. Such arrangement allows the low duty compressor to cool down gradually. If the fuel gas is freely flowing through the compressor when the compressor is not running, then lube oil pump has to run as the passing fuel gas is turning the compressor shaft and bearings have to be lubricated to avoid the damage.

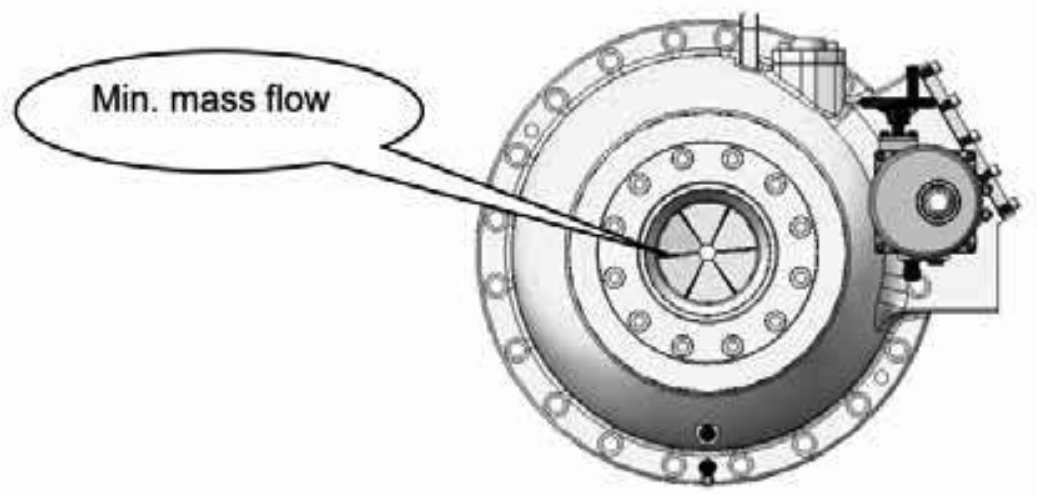

Figure 5 - Inlet guide vanes in fully closed position [19] 


\section{Conclusion}

The low duty compressor control system and delivery of fuel gas to steam boilers is a very complex system due to simultaneous control of steam generators fuel gas valves, the compressor rotor speed and IGV position control. Smooth transition in the delivery flow of fuel gas to the main steam generators is very important for the safe running mode of the low duty compressor in order to avoid surge pressures and major breakdown of the machinery. The transition from the surge area to the normal running zone of the low duty compressor is adjusted by the manufacturer but it is essential to monitor and readjust the settings if required during normal operation of the LD compressor. The opening of the surge control valve should be adjusted in such a way that the combustion process in steam generators is smoothly controlled and the LD compressor is protected in all running modes.

\section{References}

1. Cryostar CM series of compressor, https://www.yumpu.com/en/document/read/41872270/gascompressors-cryostar, (Accessed, 02.12.2019)

2. Mrzljak, V., Mrakovčić, T.: Comparison of COGES and diesel-electric ship propulsion systems, Journal of Maritime \& Transportation Sciences-Special edition No. 1, p. 131-148, 2016.

3. Centrifugal Compressor Surge-Basics, Mechanism, Mechanical engineering site, http://www. mechanicalengineeringsite.com/centrifugal-compressor-surge-basics-mechanism/, (Accessed 22.11.2019).

4. S.Y. Yoon; Z. Lin, P. E. Allaire: Control of Surge in Centrifugal Compressors by Active Magnetic Bearings Theory and Implementation, Springer-Verlag London 2013

5. McLin R.: A guide to effectively executing compressor control retrofits; Improving existing compressor control systems improves operations and energy efficiency, 2012, https://www.isa. org/standards-publications/isa-publications/intech-magazine/2012/december/process-automationa-guide-effectively-executing-compressor-control-retrofits, (Accessed 25.11.2019)

6. By TMI Staff \& Contributors: The global journal of energy equipment; Turbomachinery international,https://www.turbomachinerymag.com/compressor-surge-and-its-detection/, (Accessed 22.11.2019).

7. Gregory K. McMillan; Centrifugal and Axial COMPRESSOR CONTROL, Instrument Society of America 1983

8. LNGC Grace Barleria, Cargo operation manual, internal ship document, Hyundai Heasvy Industries LTD.

9. Mitsubishi Hitachi Power Systems, Gas Turbines M701J Series, https://www.mhps.com/products/ gasturbines/lineup/m701j/index.html, (Accessed, 22.11.2019)

10. Wartsila; Gas Turbine for Power Generation: Introduction, https://www.wartsila.com/energy/ learn-more/technical-comparisons/gas-turbine-for-power-generation-introduction, (Accessed, 22.11.2019)

11. M. P. Boyce; CENTRIFUGAL COMPRESSORS A Basic Guide, PennWell Corporation, 2003.

12. V. Mrzljak; I. Poljak; V. Medica-Viola; Dual fuel consumption and efficiency of marine steam generators for the propulsion of LNG carrier, Applied thermal engineering (1359-4311) 119 (2017); 331-346, doi:10.1016/j.applthermaleng.2017.03.078

13. Fuel gas supply controller, and system and method for supplying fuel gas with the controller, 2017-03-09 Publication of KR101713845B1, https://patents.google.com/patent/KR101713845B1/ en, (Accessed, 22.11.2019)

14. B.G. Liptak; Instrument Engineers' Handbook, Volume Two: Process Control and Optimization, Taylor and Franciss, 2005. 
15. Mrzljak, V., Anđelić, N., Poljak, I., Orović, J.: Thermodynamic analysis of marine steam power plant pressure reduction valves, Journal of Maritime \& Transportation Sciences 56 (1), p. 9-30, 2019. (doi:10.18048/2019.56.01)

16. Cryostar: Installation, Operation and Maintenance manual for a turbo compressor system, internal ship document.

17. H.V Ormer and S.V. Ormer; A practical look at inlet butterfly valves and inlet guide vanes for compressor capacity control, Plant Services, Home / Articles / 2003 / Control the blow, https:// www.plantservices.com/articles/2003/111/, (Accessed, 22.11.2019)

18. Grace Barleria, Cargo manual, internal ship document.

19. Vol. 2.6 (C) 2017Hanbell Precise Machinery Co., Ltd., http://www.hanbell.com/product/rt-tm_eng. pdf, (Accessed, 23.11.2019) 
